УДК 622.06.53.09:544.7

ФИЗИКО-ХИМИЧЕСКИЕ ПРОЦЕССЫ,

ВЫЗЫВАЮЩИЕ РОСТ КОЭФФИЦИЕНТА ИЗВЛЕЧЕНИЯ НЕФТИ ПРИ ВВЕДЕНИИ В ВОДНЫЕ РАСТВОРЫ ПРИМЕСЕЙ

НАНОРАЗМЕРНЫХ ЧАСТИЦ МЕТАЛЛОВ

PHYSICOCHEMICAL PROCESSES THAT CAUSE OIL RECOVERY

COEFFICIENT INCREASE WHEN IMPURITIES OF NANOSIZED

METAL PARTICLES ARE ADDING INTO AQUEOUS SOLUTIONS

\title{
В.И. Лесин
}

\section{Институт проблем нефти и газа РАН, г. Москва, Российская Федерация}

\section{Viktor I. Lesin}

Oil and Gas Research Institute of RAS, Moscow, Russian Federation

$$
\text { e-mail: vilesin@inbox.ru }
$$

Аннотация. Повышение эффективности технологий, основанных на закачке водных растворов в нефтяной пласт, является актуальной задачей нефтяной индустрии. Полученные в последние годы результаты лабораторных и промышленных экспериментов указывают на возможность увеличения коэффициента извлечения нефти (КИН) при введении в водные растворы примесей наноразмерных частиц оксидов металлов.

В статье дан анализ результатов лабораторных и промышленных экспериментов по использованию примесей оксидов металлов в воде с целью установления физико-химических процессов, которые сопровождают внесение таких примесей и приводят к росту эффективности применения водных растворов в системах поддержания пластового давления. 
Показано, что активной частицей, обеспечивающей спектр физикохимических процессов, приводящих к росту коэффициента извлечения нефти, является газовый микропузырек, сформировавшийся на наноразмерной частице оксида железа. Такая система (твердая частица газовый пузырек) является центром адсорбции и флотации частиц нефти благодаря наличию электрически заряженной поверхности пузырька и высокой энергии адсорбции углеводородов на поверхности оксида железа.

Внедрение частиц оксидов металлов на поверхность контакта нефть вода снижает энергию поверхностного натяжения и, следовательно, капиллярное противодавление, позволяя проникать воде в гидрофобные поры и превращать их в гидрофильные путем захвата адсорбированных в поровом пространстве углеводородов (как правило, асфальтенов и смол) частицей оксида железа, связанной с газовым пузырьком. Увеличение концентрации оксидов металлов вызывает снижение вязкости нефти. Совокупность этих физико-химических процессов позволяет значительно увеличить как приемистость инжектирующей скважины, так и рост коэффициента извлечения нефти.

Магнитные частицы оксидов железа всегда присутствуют в технических водных растворах, что позволяет значительно увеличивать концентрацию систем твердая частица - газовый пузырек путем обработки потока воды магнитным полем, не прибегая к устройствам введения примесей извне.

Abstract. Improving the efficiency of technologies based on the injection of aqueous solutions into the oil reservoir is an urgent task of the oil industry.

The results of laboratory and industrial experiments obtained in recent years indicate the possibility of increasing the oil recovery coefficient (ORC) when using aqueous solutions with admixtures of metal oxide nano sized particles.

The article analyzes the results of laboratory and industrial experiments in order to establish the physicochemical processes that accompany the introduction of such impurities and lead to an increase in the effectiveness of the use of aqueous solutions in reservoir pressure maintenance systems. 
It is shown that the particles that provide a spectrum of physicochemical processes leading to an increase ORC is a gas micro bubble formed on a nano sized iron oxide particles. Such a system (solid particle-gas bubble) it is a center of adsorption and flotation of oil particles due to the presence of an electrically charged bubble surface and high energy of adsorption of hydrocarbons on the surface of iron oxide.

The introduction of metal oxide particles on the oil-water contact surface reduces the energy of surface tension and, consequently, capillary back pressure, allowing water to penetrate into hydrophobic pores and turn them into hydrophilic by capturing hydrocarbons adsorbed in the pore space (as a rule, asphaltenes and resins) a particle of iron oxide associated with a gas bubble. An increase in the concentration of metal oxides causes a decrease in the viscosity of oil. The combination of these physicochemical processes makes it possible to significantly increase both of the well injection rate and the ORC.

Magnetic particles of iron oxides are always present in technical aqueous solutions, that makes it possible to significantly increase the concentration of solid particle-gas bubble systems by treating the water flow with a magnetic field without resorting to devices for introducing impurities from the outside.

Ключевые слова: коэффициент извлечения нефти; наноразмерные частицы; оксиды металлов; водные растворы; поровое пространство; газовый микропузырек; гидрофилизация поверхности пор; поверхностное натяжение; вязкость; адсорбция

Keywords: oil recovery coefficient; nanoscale particles; metal oxides; aqueous solutions; pore space; gas microbubble; hydrophilization of the pore surface; surface tension; viscosity; adsorption

С целью повышения коэффициента извлечения нефти (КИН), как правило, принято использовать водные растворы полимеров с вязкостью, близкой к вязкости нефти в пласте. В основе этой технологии лежит 
требование об уравнивании скорости фильтрации водного раствора полимеров и нефти [1]. С целью увеличения КИН добавляют в водные растворы и поверхностно-активные вещества для гидрофилизации порового пространства горной породы-коллектора углеводородов [2].

В лабораторных исследованиях по вытеснению нефти водой из моделей коллекторов нефти $[3,4]$ было обнаружено, что: магнитная обработка воды сопровождается увеличением скорости закачки на $\approx 30-100$ \%, увеличением КИН на $\approx 5-40 \%$ (в зависимости от состава коллектора), ростом продолжительности времени безводного вытеснения на $\approx 10-25 \%$. Отсутствие или незначительная величина эффекта обработки отмечена при использовании дистиллированной воды и большая величина эффекта - при использовании водопроводной воды.

В работах $[5,6]$ был предложен физико-химический механизм влияния магнитной обработки (МО) воды на КИН и скорость закачки воды в пористую среду, содержащую нефть. Механизм влияния МО обосновывался взаимодействием коллоидных магнитных частиц оксидов железа с адсорбированными на поверхности порового пространства углеводородами. Согласно $[5,6]$ в результате протекания воды через трубопровод, в котором сформировано магнитное поле определенной топологии и напряженности (что и представляет процедуру МО), происходит разрушение примесей агрегатов (кластеров) коллоидных магнитных частиц оксидов железа. Возникшие в результате разрушения агрегатов одиночные частицы и более мелкие коллективные структуры служат дополнительными центрами, на которых формируются газовые микропузырьки из растворенных в воде газов. Поскольку в агрегатах содержатся сотни отдельных частиц, то разрушение агрегатов может вызвать многократное увеличение концентрации центров формирования газовых пузырьков. Воздействие структуры газовый пузырек-частица оксида железа на поверхность порового пространства коллектора нефти сопровождается как увеличением гидрофильности пор, так и вовлечением в 
процесс фильтрации дополнительного количества частиц нефти за счет адсорбции частиц нефти с поверхности поры на поверхность коллоидной частицы.

В соответствии с предложенной в [6] гипотетической физикохимической моделью, основанной на роли примесей магнитных частиц оксидов железа, были разработаны конструкции магнитных устройств и методики их применения [7, 8] для повышения приемистости водонагнетательных скважин, а также снижения темпов роста отложений парафинов в насосно-компрессорных трубах скважин и наземных трубопроводов.

Промышленная апробация [9, 10] показала, что за счет магнитной обработки можно достичь увеличения темпов закачки воды на $\approx 40-100 \%$, не увеличивая давление в трубопроводе.

В лабораторных исследованиях [11-14] показано, что после добавлении в водные растворы (в том числе растворы поверхностно-активных веществ (ПАВ)) примесей наноразмерных оксидов металлов $\left(\mathrm{Al}_{2} \mathrm{O}_{3}, \mathrm{NiO}, \mathrm{SiO}_{2}, \mathrm{NiO}_{2}\right.$, $\mathrm{Fe}_{2} \mathrm{O}_{3}$ и др.) достигается дополнительный рост КИН на несколько процентов (порядка 5 \%), снижается величина поверхностного натяжения на границе вода - нефть. Совместное применение наноразмерных частиц оксидов металлов (НЧОМ) в водный раствор ПАВ препятствует адсорбции ПАВ на поверхности порового пространства, что также проявляется в росте КИН.

Исследование водопроводной воды с помощью фотометрического счетчика механических примесей СФ-12 позволило выдвинуть гипотезу о том, что наблюдавшиеся непрозрачные объекты в воде [6], протекающей через стеклянный капилляр, представляют собой газовые микропузырьки. Газовые пузырьки в воде частично отражают падающий свет и рассеивают прошедший, что вызывает снижение интенсивности зондирующего луча света. Попадание пузырька в зондирующий луч света воспринимается регистрирующей системой как непрозрачная частица с близким к радиусу пузырька радиусом R. 
В [6] было установлено присутствие устойчивых во времени газовых пузырьков малых с радиусами $\mathrm{R} \approx 10^{-4}-10^{-3}$ см, хотя при таких размерах при комнатной температуре давление $\mathrm{P}$ внутри пузырька за счет сил поверхностного натяжения $\sigma$ на границе вода - воздух должно было составлять величины $\sigma / \mathrm{R} \approx 10^{5}-10^{4} \mathrm{H} / \mathrm{M}^{2}(\approx 10-1)$ атм, при которых такие объекты не могут быть устойчивыми во времени. Кроме того, из-за выталкивающей силы, равной весу воды в пузырьках такого объема, они должны были бы быстро всплывать на поверхность и разрушаться. Концентрация частиц-пузырьков с размерами 5-10 мкм была максимальной и составляла величину порядка $\approx 1000 / \mathrm{cm}^{3}$ и резко уменьшалась до $\approx 1 / \mathrm{cm}^{3}$ для пузырьков более крупных размеров, достигавших 100 мкм.

Исследования влияния магнитной обработки на водные растворы, содержащие примеси частиц оксидов железа, проведенные путем анализа фотографий углеродных реплик поверхностей скола замороженной воды, показали наличие частиц, размеры которых под действием обработки магнитным полем уменьшались от 8 до 2 мкм. Авторы не наблюдали магнитный эффект снижения скорости отложения солей жесткости на поверхности нагревательных металлических элементов при концентрациях железа в воде 0,001-0,003 мг/л, но концентрация примеси железа 0,2-0,1 мг/л была достаточна для предотвращения отложений [15].

Авторы [15] не указали химическую природу достаточно крупных частиц, выявленных на поверхностях сколов, что дало основание предположить, что такими частицами являются газовые пузырьки, сформированные на коллоидных частицах оксидов железа [6].

Экспериментальные и теоретические исследования показывают, что газовые микропузырьки в воде могут быть устойчивыми во времени, иметь радиусы порядка 10-100 нм, образовывать кластеры (агрегаты) фрактальной структуры размерами $10^{4} \div 10^{6}$ нм. Концентрация и устойчивость таких структур обеспечивается наличием на поверхности 
пузырьков электрических зарядов, которые препятствуют растворению газа (схлопыванию пузырьков) при повышении давления [16, 17].

В [18] в составе нефти были обнаружены наноразмерные суперпарамагнитные частицы оксидов железа в составе агрегатов коллоидных частиц тяжелых фракций нефти, что подтверждает гипотезу, предложенную в [6]. Исследования нефти [19] подтвердили наличие таких частиц в концентрациях порядка нескольких граммов на тонну, что достаточно для проявления изменения физико-химических свойств нефти при воздействии постоянными и переменными электромагнитными полями.

В связи с ростом запасов тяжелой нефти, извлечение которой осложняется высокой вязкостью и гидрофобизацией порового пространства за счет адсорбция тяжелых фракций нефти на поверхности пор, исследование физико-химических механизмов воздействия коллоидных частиц для повышения эффективности добычи нефти с использованием водных растворов представляется актуальной задачей.

Полученные в последние годы новые экспериментальные и теоретические результаты позволяют предложить и обосновать детальный экспериментально и теоретически обоснованный физико-химический механизм увеличения КИН за счет введения примесей коллоидных наноразмерных частиц оксидов металлов. Такие не контролируемые частицы, в частности оксиды железа, всегда присутствуют как в природных водах, так и в скважинной нефтеводогазовой смеси, как правило, в малых количествах, измеряемых граммами на тонну веса раствора. Определение роли неконтролируемых примесей наноразмерных частиц оксидов металлов очень важно с точки зрения применения различных технологий заводнения с использованием полимеров, ПАВ, пенных систем, поскольку такие примеси могут существенно влиять на эффективность применения таких технологий. 
Физико-химический механизм роста коэффициента вытеснения нефти при использовании водных растворов, содержащих примеси коллоидных частиц оксидов металлов. Теория и экспериментальные данные

Рассмотрим коллоидную систему, образованную частицами оксидов металлов в воде. В работах [11-14] не рассматривался вопрос о возникновении агрегатов таких частиц (кластеров), объединяющих в единую структуру сотни и тысячи частиц уже при объемных концентрациях порядка $10^{-5} \%$ об., что экспериментально установлено методами рассеяния света, например в обзоре [20]. Межмолекулярное притяжение одинаковых по составу частиц приводит к образованию агрегатов фрактальной структуры, размеры которых составляют несколько микрометров, что приводит к кольматации порового пространства.

В коротком сообщении [21] говорилось об исследовании фильтрации водопроводной воды через бумажный фильтр с заявленным размером пор 2-3 мкм. Фильтрация воды привела к осаждению на поверхности фильтра значительного количества частиц железа, после магнитной обработки количество задержанных частиц уменьшилось более, чем в 2 раза. Концентрация железа в образце воды составляла 0,3 мг/л. Спектры электронного парамагнитного резонанса (ЭПР) показали, что в воде присутствуют магнитные частицы железа, которые образуют агрегаты фрактального строения [22], в данном случае с размерами, превышающими 2-3 мкм.

Сигнал ЭПР после фильтрации обработанной воды превышал исходный примерно на 40 \%. Этот парадокс, обнаруженный в 1993 г., благодаря более поздним исследованиям объясняется ростом спин-решеточной релаксации $\mathrm{T}_{\mathrm{cp}}$ с увеличением среднего объема $\mathrm{V}$ агрегатов суперпарамагнитных частиц оксидов железа: $\mathrm{T}_{\mathrm{cp}} \sim \mathrm{V}$. Величина $\mathrm{J}$ сигнала ЭПР связан с мощностью СВЧ поля в резонаторе $\mathrm{P}$, концентрацией частиц $\mathrm{N}$ и временем спин-решеточной релаксации зависимостью [23]: J PN/1+ $\mathrm{PT}_{\text {cp }}$, где $\mathrm{N}$ - общая масса частиц, 
в нашем случае масса атомов железа, зафиксированная на фильтре методом рентгеновского флуоресцентного анализа. При уменьшении $\mathrm{N}$ падение величины J при данном значении Р компенсируется уменьшением $\mathrm{T}_{\mathrm{cp}}$, что и подтверждается изменениями в спектрах ЭПР.

На рисунке 1 показаны спектры ЭПР, снятые для образцов бумажного фильтра, на котором находились магнитные частицы железа, задержанные при фильтрации простой водопроводной воды и водопроводной воды после магнитной обработки.

В образце фильтра до магнитной обработки воды (нижняя кривая) в спектре ЭПР наблюдается узкая линия, показанная стрелкой 2, с g-фактором 2,186 (+/-0,003), и полушириной на полувысоте $\Delta \mathrm{H} \approx 70$ э, которая согласно [24] вызвана наличием одиночных магнитных частиц с характерным размером порядка несколько нанометров. Эта линия отсутствует в спектре частиц после магнитной обработки воды. Очевидно, это вызвано разрушением агрегатов при прохождении через поры фильтра, поэтому на фильтре оставались мелкие фрагменты внешней рыхлой части агрегатов. После обработки магнитным полем в воде остались прочные структуры агрегатов, которые не разрушались при фильтрации, что и вызвало отсутствие мелких частиц с g-фактором 2,186.

В обоих спектрах наблюдается узкая линия с g-фактором 2, показанная стрелкой 1, которая вызвана присутствием свободных электронов находящихся в составе органических радикалов, адсорбированных на поверхности частиц. Такие линии характерны для спектров ЭПР асфальтеновых фракций нефти, представленных полициклическими молекулами углеводородов [25]. Величина сигнала ЭПР узкой линии пропорциональна интенсивности сигнала, что говорит о ее принадлежности частицам железа, а не бумажному фильтру и не адсорбированным на поверхности примесям органических веществ. Оба спектра ЭПР соответствуют спектрам фрактальных агрегатов суперпарамагнитных, 
наноразмерных частиц трехвалентного железа [24] различной фрактальной размерности.

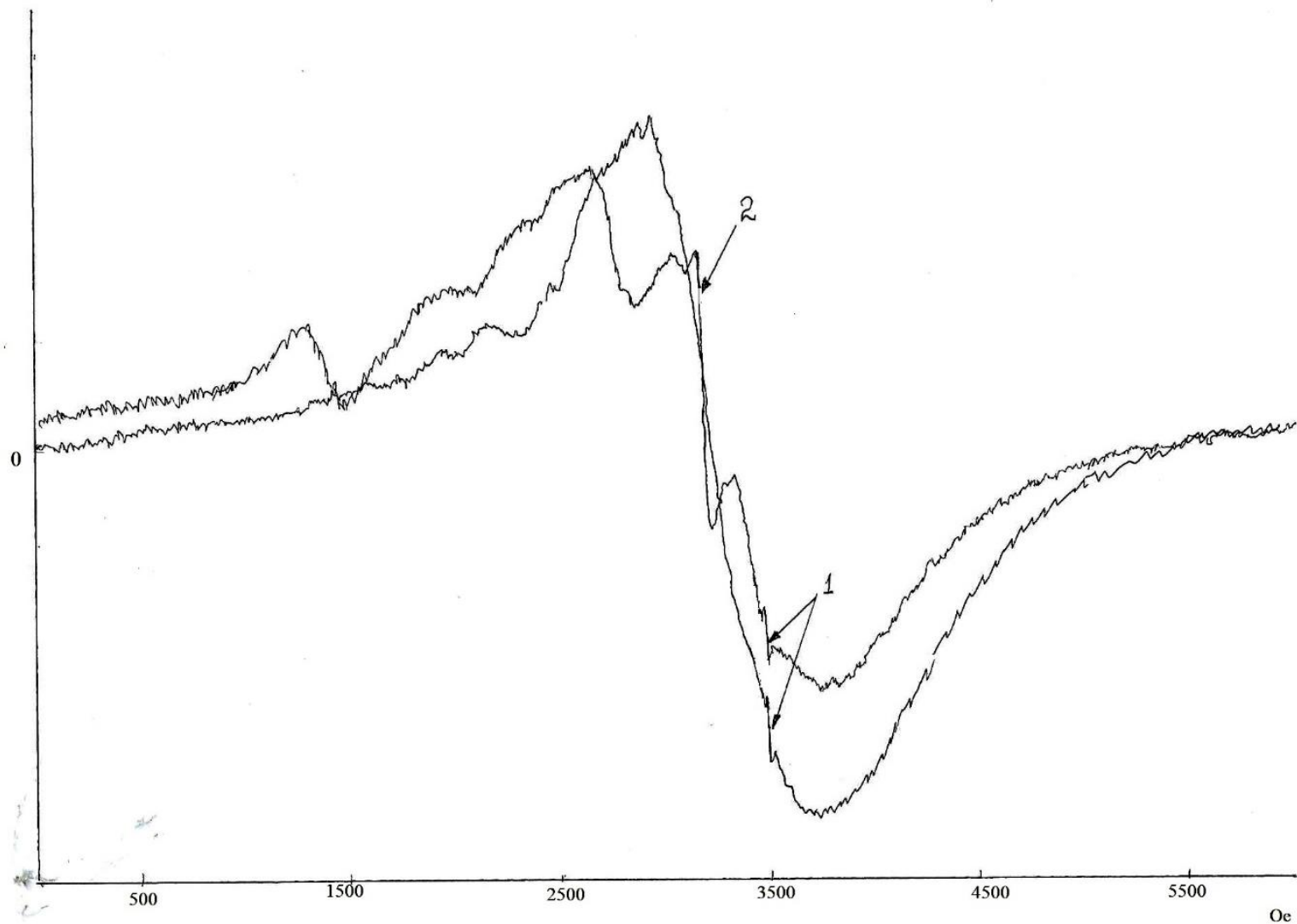

Ось абсцисс - напряженность магнитного поля Ое (эрстед)

Верхняя кривая представляет сигнал ЭПР для образца фильтра, для воды после магнитной обработки, нижняя кривая, содержащая линию, обозначенную стрелкой с цифрой 2, исходный образец, не прошедший магнитную обработку.

Рисунок 1. Спектры ЭПР, полученные для задержанных фильтром суперпарамагнитных частиц железа, снятые в одинаковых условиях

Во фрактальных агрегатах (ФА) частицы плотно прилегают друг к другу, поэтому площадь адсорбции в пересчете на одну частицу значительно меньше, чем у единичных наноразмерных частиц (НЧ). Такой агрегат, как и единичная, частица или плотный кластер малого размера, не обладающий фрактальными свойствами, представляют центры адсорбции асфальтенов и тяжелых фракций нефти, а также центры формирования газовых пузырьков. Магнитные НЧ оксидов железа в воде благодаря 
высокой энергии взаимодействия углеводородов с поверхностью позволяют практически полностью собирать на своей поверхности тяжелые фракции нефти [26]. С ростом концентрации НЧ за счет увеличения размеров их ФА рост площади поверхности, на которую адсорбируются углеводороды, главным образом асфальтены, практически останавливается и эффективность применения примесей НЧ резко снижается [11, 12]. Снижается и средняя проникающая способность НЧ из-за кольматации порового пространства.

Использование естественных примесей магнитных НЧ в воде для увеличения концентрации единичных НЧ путем разрушения ФА с помощью магнитных устройств [9, 10] является экономичным и перспективным методом увеличения приемистости нагнетающих воду скважин. Применение магнитных устройств позволяет в сотни раз увеличивать концентрацию единичных, наноразмерных частиц оксидов железа [9, 10], за счет разрушения присутствующих в воде их агрегатов, имеющих фрактальную структуру [22, 24]. Магнитные устройства, установленные в наземных водопроводах как было показано в $[9,10]$ позволили увеличить приемистость нагнетательных скважин на величину от $\approx 40$ \% до $100 \%$, при этом установка устройств предотвращала замерзание воды в зимний период.

В экспериментах по динамическому рассеянию света [16, 17] экспериментально обнаружены в водных растворах электролитов стабильные во времени газовые пузырьки, которые авторы предложили называть бабстоны. Название представляет русифицированное объединение двух английских слов - bubble (пузырь) и stone (камень). Название отражает основные характеристики этих частиц - прочность камня и химический состав - газ, поверхность бабстонов имеет электрический заряд, препятствующий схлопыванию пузырька даже при давлениях порядка ста aтмосфер.

В исследованном водном растворе $\mathrm{NaCl}$ обнаружено присутствие спонтанно возникших бабстонов с размерами, лежащими в диапазоне от 
30 нм до 1 мкм. Установлено, что средний размер радиус $\mathrm{R}_{\sigma}$ бабстона находится в диапазоне $10<\mathrm{R}_{\sigma}<100$ нм, бабстоны объединяются в агрегаты фрактального строения, содержащие 300-700 частиц, фрактальная размерность $\mathrm{D}_{\phi}$ кластеров (агрегатов) бабстонов составляет $\mathrm{D}_{\phi}=2,3-2,5, \mathrm{p}$. Плотность содержимого газовых пузырьков составляет 0,3 от плотности воды. В статье отмечено: не исключено, что бабстоны сформированы на твердых частицах наноразмеров, которые невозможно удалить путем фильтрации [17].

В работе [17] было исследовано распределение частиц по размерам в водном растворе $1 \mathrm{M} \mathrm{NaCl}$ ( $\approx 60$ г/л). При этом были обнаружены два пика в диапазоне размеров 10-100 нм и пик в диапазоне $10^{4}-10^{6}$ нм (10-1000 мкм). Распределение по размерам частиц в области пика в диапазоне 1-10 мкм отличалось большой асимметрией и слабо спадало от максимума к области предела измерения 10 мкм, что указывает на наличие газовых пузырьков. Концентрация частиц в водном растворе $\mathrm{NaCl}$ была оценена как 4•10 $0^{5} \mathrm{~m}^{-1}$, с падением концентрации солей концентрация частиц резко падала, но не исчезала даже при использовании дистиллированной воды.

В работе [27] при исследовании распределения по размерам непрозрачных частиц в водопроводной воде было обнаружено, что концентрация частиц с размерами более 5 мкм составляет несколько тысяч на cм$^{3}$, что с учетом низкой концентрации солей, которая не должна превышать 1 г/л, по порядку величины соответствует оценке работы [17].

В [27] было обнаружено, что после магнитной обработки воды как общая концентрация частиц, так и частиц в диапазонах всех размеров выросла в $\approx 3-10$ раз. После добавления растворителя оксидов железа концентрация частиц снизилась через 10 мин после введения растворителя на $\approx 25 \%$ и монотонно снижалась во времени, уменьшаясь со скоростью $\approx 10 \%$ за 5 мин. Автором [27] было высказано предположение, что зарегистрированные частицы представляют газовые пузырьки 
соответствующих размеров, сформированные на магнитных частицах оксидов железа, присутствующих в воде в концентрации порядка 0,10,2 мг/л. Как газовый пузырек так и имеющий фрактальное строение кластер пузырьков [17] представляют рассеивающие свет частицы в воде, поэтому регистрирующая система прибора воспринимает импульсы снижения интенсивности зондирующего луча освещающего капилляр, через который протекает водный раствор, как близкие по размеру непрозрачные частицы.

Недостатком гипотезы [27] являлось отсутствие доказательств возможности существования таких газовых включений, если не предполагать наличие электрических зарядов на их поверхности. Работы [16, 17] подтверждают гипотезу [27], в свою очередь, результаты [27] подтверждают предположение авторов [17] об образовании пузырьков на твердых включениях, которые присутствуют в дважды дистиллированной воде (в концентрации 0,001 мг/л [15]) и в солях $\mathrm{NaCl}$ ). Тот факт, что средняя плотность бабстона составляет примерно 0,3 от плотности воды [17] говорит о том, что, вероятно, часть объема пузырька занята твердой частицей, которой может быть частица оксида железа.

Используя данные о средней плотности бабстона, можно оценить размеры частицы оксида железа являющейся структурной составляющей бабстона. Пренебрегая массой газа в объеме бабстона m, можно оценить массу частицы оксида железа $\mathrm{m}$ как $\mathrm{m}=0,3 \rho \mathrm{V}_{\mathrm{b}}$, где $\mathrm{V}_{\mathrm{b}}$ - объем газового пузырька, $\rho$ - плотность воды. При радиусе пузырька 50 нм получаем массу частицы железа $\approx 5 \cdot 10^{-16} \quad$, что соответствует объему $\approx 0,15 \mathrm{~V}_{\mathrm{b}}=.7 \cdot 10^{-17} \mathrm{~cm}^{3}$. Откуда концентрация железа в исследованном в [17] растворе оценивается как $2 \cdot 10^{-4}$ мг/л, что по порядку величины меньше, чем в дважды дистиллированной воде [15].

Таким образом, в качестве активной частицы, вызывающей гидрофилизацию порового пространства, следует считать наноразмерный газовый пузырек, сформированный на наноразмерной частице, как правило, оксида металла. 
Наноразмерные оксиды железа обладают высокой энергией адсорбции по отношению к асфальтенам, которые снижают гидрофильность пор в результате адсорбции [25-29]. Благодаря электрическому заряду и наличию частицы оксида железа бабстон приобретает свойства поверхностно активной частицы, которая проникает в частично гидрофобизированное поровое пространство, адсорбирует с поверхности поры на частицу оксида железа частицу асфальтена, закрепленную на участке поверхности поры [25], и затем осуществляет флотационный вынос частицы асфальтена с другими углеводородами.

На полученных в [15] снимках с разрешением порядка 1-0,5 мкм/см, очевидно, были зарегистрированы коллективные структуры, образованные микропузырьками газа и зарегистрированные в $[16,17]$.

На рисунке 2 показан полученный с помощью просвечивающего микроскопа снимок частиц оксидов железа (магнетит / маггемит) с частицами нефти. Частицы нефти, поскольку снимок производился в глубоком вакууме, представлены присоединенными к их поверхностям фракциями с давлением насыщенных паров при комнатной температуре не более $10^{-4}$ мм рт. ст. К таким фракциям относятся высокомолекулярные углеводороды (смолы, асфальтены, парафины, масла). Размеры частиц оксидов железа составляют: длина 60-100 нм, диаметр 10-15 нм. При таких размерах частиц оксидов они могут без адсорбции на поверхности пор проникать в поровое пространство на глубину порядка сотен метров [13], что представляет характерное расстояние между добывающими скважинами. 


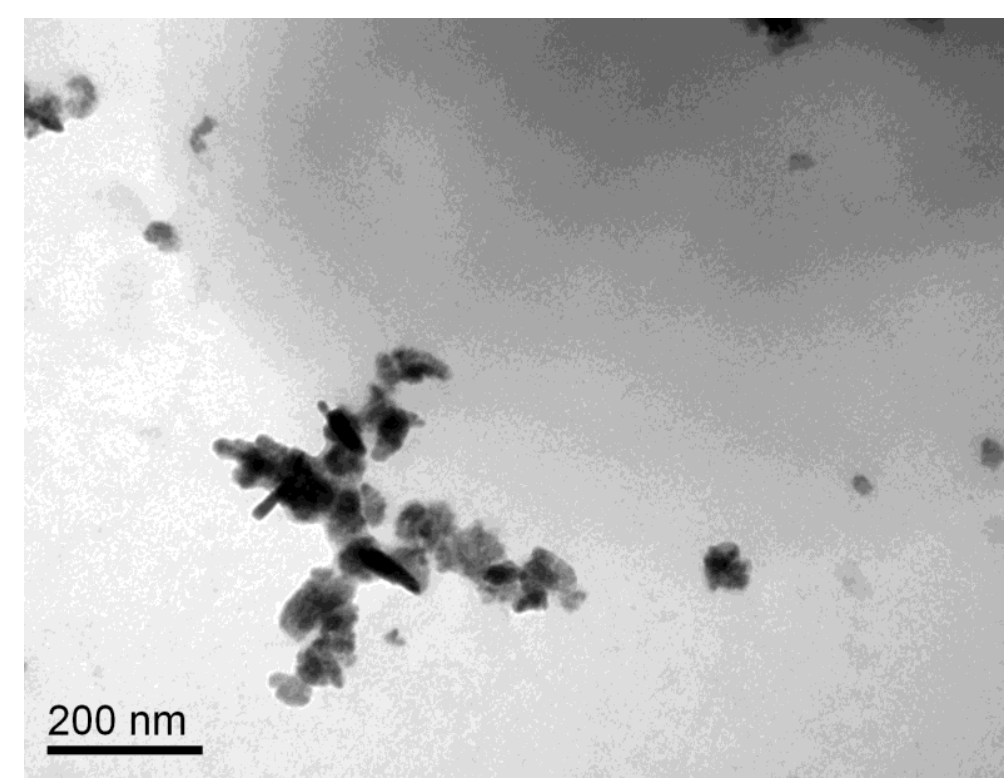

Рисунок 2. Снимок магнитных частиц оксида железа в вакууме (стержнеобразные частицы длиной порядка 60-100 нм и диаметром 10-15 нм) с адсорбированными углеводородами

Согласно многочисленным исследованиям $[11,12]$ частицы оксидов металлов концентрируются на поверхности контакта нефть - вода и снижают энергии поверхностного натяжения на границе нефть - вода, как правило, на величину порядка 10-15 \%, и, следовательно, снижают величину капиллярного давления, препятствующего движению воды и вытеснению нефти. Поскольку бабстон с частицей оксида железа представляет поверхностно-активную частицу, то такой результат является естественным следствием включения бабстонов на поверхность раздела нефть - вода.

Известно [30], что капли эмульсии нефть в воде имеют бронирующую оболочку, которая стабилизируется коллоидными твердыми частицами, имеющими электрический заряд и покрытыми слоем адсорбированных углеводородов. Благодаря такому составу наиболее энергетически выгодным расположением такой частицы является частичное погружение как в нефтяную, так и водяную среду. Бронирующая оболочка препятствует слиянию капель нефти в воде, ее разрушение требует значительных затрат энергии. В качестве одного из методов разрушения бронирующих оболочек 
применяется обработка эмульсии магнитными устройствами, которые разрушают агрегаты магнитных частиц оксидов железа и, как следствие, разрушают эмульсии, разрушая и удаляя частицы железа из бронирующих оболочек.

Использование оксидов металлов, как вытекает из приведенного анализа физико-химических процессов, является перспективным методом увеличения КИН. Однако использование искусственно введенных оксидов металлов представляет довольно сложную техническую задачу, особенно в зимнее время, требуя высоких затрат как на устройства, так и на оксиды дорогостоящих металлов. Наиболее перспективным методом реализации этой технологии является использование магнитных устройств, обеспечивающих дробление агрегатов примесей магнитных оксидов железа. Примеси таких частиц присутствуют практически во всех естественных и технических водных растворах. Применение магнитных устройств уже показало свою технологичность и перспективность в условиях эксплуатации водоводов на месторождении, в том числе и в зимнее время $[9,10]$.

Отметим, что оксиды железа обладают каталитическими свойствами [31-34], которые позволяют вызывать деструкцию асфальтенов уже при температурах порядка 50-100 ${ }^{\circ} \mathrm{C}$, что позволяет снижать вязкость и повышать долю легких фракций нефти уже в пласте.

Внедрение наноразмерных частиц железа в нефть позволяет многократно снижать ее вязкость $[35,36]$ за счет уменьшения размеров агрегатов частиц нефти в результате перераспределения коллоидных частиц по увеличенному количеству центров формирования агрегатов, которыми являются частицы оксидов металлов. Снижение вязкости способствует росту КИН за счет роста подвижности нефти и улучшения фильтрации через поры малых размеров.

Естественные примеси коллоидных частиц открывают перспективы роста КИН под воздействием электрических полей, что подтверждается 
экспериментальными исследованиями по снижению вязкости под действием импульсных электрических полей [37].

\section{Выводы}

Проведенный анализ позволяет сделать вывод о том, что физикохимический механизм воздействия наноразмерных частиц металлов на коэффициент извлечения нефти и гидрофилизацию порового пространства коллектора заключается в том, что

- в водном растворе образуются поверхностно-активные частицы, состоящие из пузырька газа с поверхностным электрическим зарядом и наноразмерной частицы оксида металла, например железа;

- активные частицы, проникая в гидрофобизированную пору, адсорбируют на поверхность наночастицы оксида металла частицу нефти, что сопровождается гидрофилизацией поры и вовлечением адсорбированной нефти в процесс фильтрации по направлению к добывающей скважине;

- наноразмерные частицы оксидов металлов концентрируются на поверхности раздела нефть - вода и снижают энергию поверхностного натяжения, снижая капиллярное противодавление;

- внедряясь в нефть, частицы оксидов металлов снижают вязкость за счет уменьшения размеров фрактальных агрегатов коллоидных частиц нефти в результате увеличения количества центров роста агрегатов. Уменьшение размеров агрегатов приводит к улучшению фильтрации через поры малых размеров.

Перспективным методом увеличения концентрации наноразмерных частиц является обработка магнитным полем воды, содержащей примеси магнитных частиц оксидов железа или иных металлов.

Работа выполнена в соответствии федеральной программой РАНО1392019-0005 (Исследование термодинамических свойств углеводородньх 
смесей, моделирование гидротермодинамических, физико-химических и геомеханических проиессов в геосредах с иелью повышения эффрективности разработки трудноизвлекаемых запасов нефти и газа).

\section{Список используемых источников}

1. Абиров Р.Ж., Мухамедова А.Г., Панабеккызы Б., Еремин Н.А., Абиров Ж.Ж., Нестеркин А.А. Опытно промышленное внедрение полимерного заводнения Южно-Тургайского бассейна // Нефтепромысловое дело. 2016. № 5. С. 15-19.

2. Рузин Л.М., Морозюк О.А. Методы повышения нефтеотдачи пластов (теория и практика). Ухта: УГТУ, 2014. 126 с.

3. Байрамов А.М., Мамед-Заде А.М., Михайлов В.М., Неретин В.Д. Влияние магнитной обработки воды на процесс вытеснения // Известия ВУЗов. Нефть и газ. 1977. № 12. С. 25-29.

4. Михельман А.И., Федорив Л.В., Радыш В.И. Изменение нефтеотдачи пласта при вытеснении нефти намагниченной водой // Известия ВУЗов. Нефть и газ. 1977. № 12. С. 78-90.

5. Лесин В.И., Михайлов Н.Н., Сечина Л.С. Использование коллоидных частиц железа в воде для модификации поверхности порового пространства коллекторов нефти и газа // Геология, геофизика и разработка нефтяных и газовых месторождений. 2002. № 5. С. 78-81.

6. Лесин В.И. Физико-химические основы применения магнитных полей в процессах добычи, транспортировки, разработки и подготовки нефти // Фундаментальный базис нефтегазовых технологий: в кн. М.: Геос, 2003. C. $130-135$.

7. Пат. 2098604 РФ, МПК Е 21 В 37/00. Устройство для магнитной обработки жидкости / В.И. Лесин, И.Р. Василенко. 95121325/03, Заявлено 26.12.1995; Опубл. 10.12.1997 
8. Пат. 2169033 РФ, МПК В 01 D 17/06. Устройство для магнитной обработки движущейся нефтеводогазовых смесей / В.И. Лесин. 2000107996/12, Заявлено 03.04.2000; Опубл. 20.06.2001.

9. Муслимов Р.Х., Хисамов Р.С., Сулейманов Э.И., Хавкин А.Я., Лесин В.И., Василенко И.Р. Повышение приемистости нагнетательных скважин с помощью магнитных устройств в НГДУ «Иркенефть» // Нефтяное хозяйство. 1998. № 7. С. 24-25.

10. Муслимов Р.X. Становление и развитие новейших технологий разработки нефтяных месторождений на страницах журнала «Нефтяное хозяйство» // Нефтяное хозяйство. 2010. № 10. С. 10-15.

11. Fakoya M.F., Patel Y., Shah S. Nanotechnology: Innovative Application in the Oil and Gas Industry // International Journal of Global Advanced Materials and Nanotechnology. 2018. Vol. 1. No. 5. P. 16-30.

12. Sun X., Zhang Y., Chen G., Gai Z. Application of Nanoparticles in Enhanced Oil Recovery: a Critical Review of Recent Progress // Energies. 2017. Vol. 10. P. 345-378. DOI: 10.3390/en10030345.

13. Rahmani A.R., Bryant S., Huh C., Athey A., Ahmadian M., Chen J., Wilt M. Crosswell Magnetic Sensing of Superparamagnetic Nanoparticles for Subsurface Applications // SPE Journal. 2015. Vol. 20. Issue 5. P. 1067-1082. Paper Number SPE-166140-PA. DOI: 10.2118/166140-PA.

14. Mishahghassemi S., Lead J.R. Oil Recovery from Water under Environmentally Relevant Conditions Using Magnetic Nanoparticles // Environmental Science Technology. 2015. Vol. 49. Issue 19. P. 11729-11736. DOI: 10.1021/acs.est.5b02687.

15. Мартынова О.И., Гусев Я.Т., Леонтьев Е.А. К вопросу о механизме влияния магнитного поля на водные растворы солей // Успехи физических наук. 1969. Т. 98. Вып. 1. C. 195-199. DOI: 10.3367/UFNr.0098.196905n. 0195.

16. Bunkin N.F., Bunkin F.V. Bubston Structure of Water and Electrolyte Aqueous Solutions // Physics-Uspekhi. 2016. Vol. 59. Issue 9. P. 846-865. DOI: 10.3367/UFNe.2016.05.037796. 
17. Бункин Н.Ф., Шкирин А.В. Исследование бабстонно-кластерной структуры воды и водных растворов электролитов методами лазерной диагностики // Труды ИОФАН. 2013. Т. 69. С. 3-57.

18. Лесин В.И., Кокшаров Ю.А., Хомутов Г.Б. Магнитные наночастицы в нефти // Нефтехимия. 2010. Т. 50. № 2. С. 114-117.

19. Moscon P.S., Pessoa M.S., Rodrigues M.C.R., Alves A.L., Flores E.M.M., Passamani E.C., Vicente M.A., Santos M.F.P. Investigation of the Naturally Occurring Magnetic Nanoparticles in Crude Oil by AC Magnetic Susceptibility Experiment // Journal of Superconductivity and Novel Magnetism. 2021. Vol. 34. P. 2855-2863. DOI: 10.1007/s10948-021-05971-2.

20. Ролдугин В.И. Свойства фрактальных дисперсных систем // Успехи химии. 2003. Т. 72. № 11. С. 1027-1054.

21. Lesin V.I., Dunin A.G., Khavkin A.Ya. Changes in Physical and Chemical Properties of Aqueous Solutions Induced by an Electromagnetic Field // Russian Journal of Physical Chemistry. 1993. Vol. 67. № 7. P. 1403-1404.

22. Brunner M., Gall S., Wilke W., Zrinyi M. Formation of Fractal Structures by Aggregation of Anisometric Iron(III) Hydroxide Particles // Physica A: Statistical Mechanics and its Applications. 1995. Vol. 214. P. 153-161.

23. Эмануэль Н.М., Кнорре Д.Г. Курс химической кинетики. М.: Высшая школа, 1984. 463 с.

24. Noginov M.M., Noginova N.N., Amponsah O., Bah R., Rakhimov R., Atsarkin V.A. Magnetic Resonance in Iron Oxide Nanoparticles: Quantum Features and Effect of Size // Journal of Magnetism and Magnetic Materials. 2008. Vol. 320. Issue 18. P. 2228-2232. DOI: 10.1016/j.jmmm.2008.04.154.

25. Гальцев В.Е., Аметов И.М., Дзюбенко Е.М., Кузнецов А.М., Ковалев А.Г., Сальников Д.И. Влияние образования надмолекулярных структур на фильтрацию нефти в пористой среде // Коллоидный журнал. 1995. Т. 57. № 5. C. 660-665. 
26. Mishahghassemi S., Lead J.R. Oil Recovery from Water under Environmentally Relevant Conditions Using Magnetic Nanoparticles // Environmental Science and Technology. 2015. Vol. 49. Issue 19. P. 11729-11736. DOI: 10.1021/acs.est.5b02687.

27. Лесин В.И. Физико-химическая модель изменения нефтевытесняющих свойств воды после ее магнитной обработки // Нефтепромысловое дело. 2001. № 3. С. 15-17.

28. Михайлов Н.Н., Ермилов О.М., Сечина Л.С. Изменение смачиваемости пород-коллекторов при адсорбции асфальтенов на внутрипоровой поверхности // Актуальные проблемы нефти и газа. 2021. Вып. 1 (32). C. 3-15. DOI: 10.29222/ipng.2078-5712.2021-32.art1.

29. Mikhailov N.N., Ermilov O.M., Sechina L.S. Effect of Asphaltenes on Wettability of Gas and Oil Saturated Reservoir Rocks // Doklady Earth Sciences. 2019. Vol. 486. P. 465-467. DOI: 10.1134/S1028334X19050040.

30. Сафиева Р.3., Магадова Л.А., Климова Л.З., Борисова О.А. Физикохимические свойства нефтяных дисперсных систем. М.: Изд-во РГУ нефти и газа им. И.М. Губкина, 2001. 60 с.

31. Лесин В.И. Физические основы обработки магнитным полем коллоидных систем, участвующих в процессах добычи, транспортировки и подготовки нефти // Актуальные проблемы нефти и газа. 2018. Вып. 1 (20). C. 25. DOI: 10.29222/ipng.2078-5712.2018-20.art25.

32. Nassar N.N., Hassan A., Pereira-Almao P. Comparative Oxidation of Adsorbed Asphaltenes onto Transition Metal Oxide Nanoparticles // Colloids and Surfaces A: Physicochemical and Engineering Aspects. 2011. Vol. 384. Issue 13. P. 145-149. DOI: 10.1016/j.colsurfa.2011.03.049.

33. Nassar N.N., Hassan A., Carbognari L., Lopes-Linares F., Pereira-Almao P. Iron Oxide Nanoparticles for Rapid Adsorption and Enhanced Catalytic Oxidation of Thermally Cracked Asphaltenes // Fuel. 2012. Vol. 95. P. 257-262. DOI: 10.1016/j.fuel.2011.09.022. 
34. Лесин В.И., Лесин С.В., Иванов Е.В. Окислительный крекинг нефти пероксидом водорода в присутствии наночастиц оксида железа // Наногетерогенный катализ. 2017. Т. 2. № 1. С. 38-42. DOI: $10.1134 / \mathrm{S} 2414215817010063$.

35. Aristizabal-Fontal J.E., Cortes F.B., Franco C.A. Viscosity Reduction of Extra Heavy Crude Oil by Magnetite Nanoparticle-Based Ferrofluids // Adsorption Science and Technology. 2018. Vol. 36. Issue 1-2. P. 23-45. DOI: $10.1177 / 0263617417704309$.

36. Лесин В.И. Математическая модель вязкости тяжелой нефти, содержащей примеси коллоидных наночастиц оксидов металлов // Сетевое издание «Нефтегазовое дело». 2019. № 2. С. 199-216. URL: http://ogbus.ru/files/ogbus/issues/2_2019/ogbus_2_2019_p199-216.pdf (дата обращения: 29.08.2021). DOI: 10.17122/ogbus-2019-2-199-216.

37. Tao R., Tang H. Reducing Viscosity Of Paraffin Based Crude Oil with Electric Field for Oil Production and Transportation // Fuel. 2014. Vol. 118. P. 69-72. DOI: 10.1016/j.fuel.2013.10.056.

\section{References}

1. Abirov R.Zh., Mukhamedova A.G., Panabekkyzy B., Eremin N.A., Abirov Zh.Zh., Nesterkin A.A. Opytno promyshlennoe vnedrenie polimernogo zavodneniya Yuzhno-Turgaiskogo basseina [Pilot Introduction of the Polymer Flooding in the Oilfield of South Turgay Basin]. Neftepromyslovoe delo-Oilfield Engineering, 2016, No. 5, pp. 15-19. [in Russian].

2. Ruzin L.M., Morozyuk O.A. Metody povysheniya nefteotdachi plastov (teoriya i praktika) [Enhanced Oil Recovery Methods (Theory and Practice)]. Ukhta, UGTU Publ., 2014. 126 p. [in Russian].

3. Bairamov A.M., Mamed-Zade A.M., Mikhailov V.M., Neretin V.D. Vliyanie magnitnoi obrabotki vody na protsess vytesneniya [Influence of Magnetic Water Treatment on the Displacement Process]. Izvestiya VUZov. Neft' i gaz-Izvestiya VUZov. Oil and Gas, 1977, No. 12, pp. 25-29. [in Russian]. 
4. Mikhelman A.I., Fedoriv L.V., Radysh V.I. Izmenenie nefteotdachi plasta pri vytesnenii nefti namagnichennoi vodoi [Change in Oil Recovery from Oil Displacement by Magnetized Water]. Izvestiya VUZov. Neft' $i$ gaz - Izvestiya VUZov. Oil and Gas, 1977, No. 12, pp. 78-90. [in Russian].

5. Lesin V.I., Mikhailov N.N., Sechina L.S. Ispol'zovanie kolloidnykh chastits zheleza $\mathrm{v}$ vode dlya modifikatsii poverkhnosti porovogo prostranstva kollektorov nefti i gaza [The Use of Colloidal Iron Particles in Water to Modify the Surface of the Pore Space of Oil and Gas Reservoirs]. Geologiya, geofizika $i$ razrabotka neftyanykh i gazovykh mestorozhdenii - Geology, Geophysics and Development of Oil and Gas Fields, 2002, No. 5, pp. 78-81. [in Russian].

6. Lesin V.I. Fiziko-khimicheskie osnovy primeneniya magnitnykh polei v protsessakh dobychi, transportirovki, razrabotki i podgotovki nefti [Physicochemical Foundations of the Application of Magnetic Fields in the Processes of Production, Transportation, Development and Preparation of Oil]. $V$ knige «Fundamental'nyi bazis neftegazovykh tekhnologii» [In the Book «Fundamental Basis of Oil and Gas Technologies»]. Moscow, Geos Publ., 2003. pp. 130-135. [in Russian].

7. Lesin V.I., Vasilenko I.R. Ustroistvo dlya magnitnoi obrabotki zhidkosti [Device for Magnetic Treatment of Liquids]. Patent RF, No. 2098604, 1997. [in Russian].

8. Lesin V.I. Ustroistvo dlya magnitnoi obrabotki dvizhushcheisya neftevodogazovykh smesei [Device for Magnetic Processing of Moving OilWater-Gas Mixtures]. Patent RF, No. 2169033, 2001. [in Russian].

9. Muslimov R.Kh., Khisamov R.S., Suleimanov E.I., Khavkin A.Ya., Lesin V.I., Vasilenko I.R. Povyshenie priemistosti nagnetatel'nykh skvazhin s pomoshch'yu magnitnykh ustroistv v NGDU «Irkeneft'»[Increasing the Injectivity of Injection Wells Using Magnetic Devices at NGDU «Irkeneft»]. Neftyanoe khozyaistvo - Oil Industry, 1998, No. 7, pp. 24-25. [in Russian]. 
10. Muslimov R.Kh. Stanovlenie i razvitie noveishikh tekhnologii razrabotki neftyanykh mestorozhdenii na stranitsakh zhurnala «Neftyanoe khozyaistvo» [Formation and Development of the Latest Technologies for the Development of Oil Fields on the Pages of the Journal «Oil Industry»]. Neftyanoe khozyaistvo Oil Industry, 2010, No. 10, pp. 10-15. [in Russian].

11. Fakoya M.F., Patel Y., Shah S. Nanotechnology: Innovative Application in the Oil and Gas Industry. International Journal of Global Advanced Materials and Nanotechnology, 2018, Vol. 1, No. 5, pp. 16-30.

12. Sun X., Zhang Y., Chen G., Gai Z. Application of Nanoparticles in Enhanced Oil Recovery: a Critical Review of Recent Progress. Energies, 2017, Vol. 10, pp. 345-378. DOI: 10.3390/en10030345.

13. Rahmani A.R., Bryant S., Huh C., Athey A., Ahmadian M., Chen J., Wilt M. Crosswell Magnetic Sensing of Superparamagnetic Nanoparticles for Subsurface Applications. SPE Journal, 2015, Vol. 20, Issue 5, pp. 1067-1082, Paper Number SPE-166140-PA. DOI: 10.2118/166140-PA.

14. Mishahghassemi S., Lead J.R. Oil Recovery from Water under Environmentally Relevant Conditions Using Magnetic Nanoparticles. Environmental Science Technology, 2015, Vol. 49, Issue 19, pp. 11729-11736. DOI: 10.1021/acs.est.5b02687.

15. Martynova O.I., Gusev Ya.T., Leontev E.A. K voprosu o mekhanizme vliyaniya magnitnogo polya na vodnye rastvory solei [Concerning the Mechanism of the Influence of a Magnetic Field of Aqueous Solutions of Salts]. Uspekhi fizicheskikh nauk - Uspekhi Fizicheskikh Nauk, 1969, Vol. 98, Issue 1, pp. 195199. DOI: 10.3367/UFNr.0098.196905n.0195. [in Russian].

16. Bunkin N.F., Bunkin F.V. Bubston Structure of Water and Electrolyte Aqueous Solutions. Physics-Uspekhi, 2016, Vol. 59, Issue 9, pp. 846-865. DOI: 10.3367/UFNe.2016.05.037796. 
17. Bunkin N.F., Shkirin A.V. Issledovanie babstonno-klasternoi struktury vody i vodnykh rastvorov elektrolitov metodami lazernoi diagnostiki [Study of Bubston-Cluster Structure of Water and Aqueous Electrolyte Solutions by Methods of Laser Diagnostics]. Trudy IOFAN - Proceedings of IOFAN, 2013, Vol. 69, pp. 3-57. [in Russian].

18. Lesin V.I., Koksharov Yu.A., Khomutov G.B. Magnitnye nanochastitsy v nefti [Magnetic Nanoparticles in Petroleum]. Neftekhimiya - Neftekhimiya, 2010, Vol. 50, No. 2, pp. 114-117. [in Russian].

19. Moscon P.S., Pessoa M.S., Rodrigues M.C.R., Alves A.L., Flores E.M.M., Passamani E.C., Vicente M.A., Santos M.F.P. Investigation of the Naturally Occurring Magnetic Nanoparticles in Crude Oil by AC Magnetic Susceptibility Experiment. Journal of Superconductivity and Novel Magnetism, 2021, Vol. 34, pp. 2855-2863. DOI: 10.1007/s10948-021-05971-2.

20. Roldugin V.I. Svoistva fraktal'nykh dispersnykh sistem [Fractal Structures in Disperse Systems]. Uspekhi khimii - Russian Chemical Reviews, 2003, Vol. 72, No. 11, pp. 1027-1054. [in Russian].

21. Lesin V.I., Dunin A.G., Khavkin A.Ya. Changes in Physical and Chemical Properties of Aqueous Solutions Induced by an Electromagnetic Field. Russian Journal of Physical Chemistry, 1993, Vol. 67, № 7, pp. 1403-1404.

22. Brunner M., Gall S., Wilke W., Zrinyi M. Formation of Fractal Structures by Aggregation of Anisometric Iron(III) Hydroxide Particles. Physica A: Statistical Mechanics and its Applications, 1995, Vol. 214, pp. 153-161.

23. Emanuel N.M., Knorre D.G. Kurs khimicheskoi kinetiki [Chemical Kinetics Course]. Moscow, Vysshaya shkola Publ., 1984. 463 p. [in Russian].

24. Noginov M.M., Noginova N.N., Amponsah O., Bah R., Rakhimov R., Atsarkin V.A. Magnetic Resonance in Iron Oxide Nanoparticles: Quantum Features and Effect of Size. Journal of Magnetism and Magnetic Materials, 2008, Vol. 320, Issue 18, pp. 2228-2232. DOI: 10.1016/j.jmmm.2008.04.154. 
25. Galtsev V.E., Ametov I.M., Dzyubenko E.M., Kuznetsov A.M., Kovalev A.G., Salnikov D.I. Vliyanie obrazovaniya nadmolekulyarnykh struktur na fil'tratsiyu nefti v poristoi srede [Influence of the Formation of Supramolecular Structures on Oil Filtration in a Porous Medium]. Kolloidnyi zhurnal-Colloid Journal, 1995, Vol. 57, No. 5, pp. 660-665. [in Russian].

26. Mishahghassemi S., Lead J.R. Oil Recovery from Water under Environmentally Relevant Conditions Using Magnetic Nanoparticles. Environmental Science and Technology, 2015, Vol. 49, Issue 19, pp. 1172911736. DOI: 10.1021/acs.est.5b02687.

27. Lesin V.I. Fiziko-khimicheskaya model' izmeneniya neftevytesnyayushchikh svoistv vody posle ee magnitnoi obrabotki [Physicochemical Model of Changes in Oil-Displacing Properties of Water after Magnetic Treatment]. Neftepromyslovoe delo-Oilfield Engineering, 2001, No. 3, pp. 15-17. [in Russian].

28. Mikhailov N.N., Ermilov O.M., Sechina L.S. Izmenenie smachivaemosti porod-kollektorov pri adsorbtsii asfal'tenov na vnutriporovoi poverkhnosti [Wettability Change of Reservoir Rocks During the Adsorption of Asphaltenes on the Interstitial Surface]. Aktual'nye problemy nefti i gaza-Actual Problems of Oil and Gas, 2021, Issue 1 (32), pp. 3-15. DOI: 10.29222/ipng.2078-5712.202132.art1. [in Russian].

29. Mikhailov N.N., Ermilov O.M., Sechina L.S. Effect of Asphaltenes on Wettability of Gas and Oil Saturated Reservoir Rocks. Doklady Earth Sciences, 2019, Vol. 486, pp. 465-467. DOI: 10.1134/S1028334X19050040.

30. Safieva R.Z., Magadova L.A., Klimova L.Z., Borisova O.A. Fizikokhimicheskie svoistva neftyanykh dispersnykh sistem [Physicochemical Properties of Oil Dispersed Systems]. Moscow, RGU nefti i gaza im. I.M. Gubkina Publ., 2001. 60 p. [in Russian]. 
31. Lesin V.I. Fizicheskie osnovy obrabotki magnitnym polem kolloidnykh sistem, uchastvuyushchikh $\mathrm{v}$ protsessakh dobychi, transportirovki i podgotovki nefti [Physical Basis of Magnetic Field Treatment of Colloidal Systems Involved in Oil and Gas Industry Processes]. Aktual'nye problemy nefti i gaza - Actual Problems of Oil and Gas, 2018, Issue 1 (20), pp. 25. DOI: 10.29222/ipng.20785712.2018-20.art25. [in Russian].

32. Nassar N.N., Hassan A., Pereira-Almao P. Comparative Oxidation of Adsorbed Asphaltenes onto Transition Metal Oxide Nanoparticles. Colloids and Surfaces A: Physicochemical and Engineering Aspects, 2011, Vol. 384, Issue 13, pp. 145-149. DOI: 10.1016/j.colsurfa.2011.03.049.

33. Nassar N.N., Hassan A., Carbognari L., Lopes-Linares F., Pereira-Almao P. Iron Oxide Nanoparticles for Rapid Adsorption and Enhanced Catalytic Oxidation of Thermally Cracked Asphaltenes. Fuel, 2012, Vol. 95, pp. 257-262. DOI: 10.1016/j.fuel.2011.09.022.

34. Lesin V.I., Lesin S.V., Ivanov E.V. Okislitel'nyi kreking nefti peroksidom vodoroda v prisutstvii nanochastits oksida zheleza [Oxidative Cracking of Oil with Hydrogen Peroxide in the Presence of iron Oxide Nanoparticles]. Nanogeterogennyi kataliz - Nanoheterogeneous Catalysis, 2017, Vol. 2, No. 1, pp. 38-42. DOI: 10.1134/S2414215817010063. [in Russian].

35. Aristizabal-Fontal J.E., Cortes F.B., Franco C.A. Viscosity Reduction of Extra Heavy Crude Oil by Magnetite Nanoparticle-Based Ferrofluids. Adsorption Science and Technology, 2018, Vol. 36, Issue 1-2, pp. 23-45. DOI: $10.1177 / 0263617417704309$.

36. Lesin V.I. Matematicheskaya model' vyazkosti tyazheloi nefti, soderzhashchei primesi kolloidnykh nanochastits oksidov metallov [Viscosity Mathematical Model of Heavy Oil Containing the Metal Oxides Colloid Nanoparticles Impurity]. Setevoe izdanie «Neftegazovoe delo» - Online Edition «Oil and Gas Business», 2019, No. 2, pp. 199-216. URL: http://ogbus.ru/files/ogbus/issues/2_2019/ogbus_2_2019_p199-216.pdf (accessed 29.08.2021). DOI: 10.17122/ogbus-2019-2-199-216. [in Russian]. 
37. Tao R., Tang H. Reducing Viscosity Of Paraffin Based Crude Oil with Electric Field for Oil Production and Transportation. Fuel, 2014, Vol. 118, pp. 69-72. DOI: 10.1016/j.fuel.2013.10.056.

\section{Сведения об авторе}

\section{About the author}

Лесин Виктор Иванович, канд. физ.-мат. наук, ведущий научный сотрудник, Институт проблем нефти и газа Российской Академии наук (ИПНГ РАН), г. Москва, Российская Федерация

Viktor I. Lesin, Candidate of Physics and Mathematics Sciences, Leading Researcher, Oil and Gas Research Institute of Russian Academy of Sciences, Moscow, Russian Federation

e-mail: vilesin@inbox.ru 